\title{
Load flow analysis of 10 bus loop distribution network excited by a generator simulated using open modelica editor
}

\author{
P. Abirami ${ }^{1}$, C. N. Ravi ${ }^{2}$ \\ ${ }^{1}$ EEE, Sathyabama Institute of Science and Technology, Chennai, India \\ ${ }^{2}$ EEE Vidya Joythi Institute of Technology, Hyderabad, india
}

\section{Article Info \\ Article history: \\ Received Oct 9, 2020 \\ Revised Mar 17, 2021 \\ Accepted Mar 28, 2021}

\section{Keywords:}

Automatic voltage regulator

IPSL

Load flow analysis

Power system stabilizer

\begin{abstract}
In recent days, due to advancement in technology, the end users are facing severe power quality issues. Load flow analysis is one of the fundamental methodologies in solving power network problems. The key importance of load flow analysis is to improve the performance of distribution network. The main intention of this reserach is to carry out the load flow and voltage stability analysis of 10 bus loop distribution network energized by a generator. Load flow analysis is carried out by using Newton Raphson method. The per unit voltage and angle of the proposed network is determined in all 10 buses by load flow analysis. The voltage stability analysis is implemented by introducing a fault in the network. Here, a power fault is injected at bus 4 between the time interval of 2 to $3 \mathrm{sec}$ to analyse the stability of the system. The voltage stability of the system is analysed for the network with and without automatic voltage regulator (AVR). The AVR unit is tuned by using power system stabilizer (PSS). The results are examined by simulating the network using openmodelica connection editor. From the simulation results the per unit voltages and angles at all 10 buses are determined for the network with and without AVR. By comparing both the results it is proved that the network with AVR has better voltage stability than the other. Thus, the voltage stability of the system is improved by connecting the generator with AVR and PSS.
\end{abstract}

This is an open access article under the CC BY-SA license.

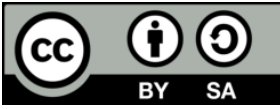

\section{Corresponding Author:}

P. Abirami

EEE, Sathyabama Institute of Science and Technology, Chennai, India

Email: abiramiramkumar80@gmail.com

\section{INTRODUCTION}

In this modern civilization, the electrical utilities need to be automated to fulfill the requirements of human activities. For automation various control processes are implemented to control the utilities. These processes may be of linear or non-linear in nature which results in reducing the quality of power. In current situation the demand for electricity increases like the increase in demand for gold in our country. So, we should ensure that all the end users are supplied with quality power [1]-[3]. One can be confident about the power quality when there is enough knowledge about stability of voltages, different bus angles and power flows in a network. Hence, it is necessary to analyze power or load flow studies of network (either transmission or distribution) to enhance its efficiency and quality [4]-[6]. Depends on the power flow studies the following buses are framed, a) slack or reference bus, b) generator bus, and c) load bus

Here, the slack bus is provided with both voltage magnitude and angle. So, it is also called as reference bus in the network. The generator bus is called as PV bus because the real power and voltage magnitude are specified for it [7], [8]. The load buses they are generally known as PQ buses [9], [10]. The per unit magnitude and phase angle of voltage for load buses are determined by using numerical methods 
[11]. The numerical methods include Newton's Raphson method, Gauss Seidel Method, Fast decoupled method etc [12], [13]. In this research work, a well-conditioned power flow problem is framed and solved using Newton-Raphson method. In NR technique, the non-linear equations are solved by polar coordinate method. [14]-[16].

In general, NR method follows the steps,

Step 1 : An admittance matrix is framed.

Step 2 : Initial voltage magnitude and phase angles are assigned to all the load buses connected in the network.

Step 3 : Calculate P and Q for all load buses.

Step 4 : Frame a Jacobian matrix.

Step 5 : Determine $\Delta \mathrm{Vi}$ and $\Delta \delta$ i by using Jacobian matrix.

Step 6 : Update the voltage magnitude and phase angle for all the load buses.

Step 7 : Continue with consecutive iterations until the real and reactive powers are within the specified range [17]-[19].

The open modelica software is an open-source software and the circuit design is purely dependant on the components from Itesla Power System Library. Since, most of the loads used today are of non linear in nature, they inject harmonics in the distribution network [20]-[22]. These harmonics results in voltage disturbances in the system. Though several methodologies like implementing custom FACT devices, filtering techniques are introduced to reduce the harmonics, load flow and stability analysis are the prime significant methodologies to perform detailed analysis of per unit voltages at all buses [23]-[25].

The paper is organized in such a way that Section 2 explains the proposed 10 bus loop distribution system. Section 3 describes the simulation results of load flow analysis of the distribution network with and without AVR and PSS. Also, comparison of the simulation results is tabulated in Section 4. Section 5 concludes the power flow analysed for the networks.

\section{PROPOSED 10 BUS LOOP DISTRIBUTION NETWORKS}

The single line diagram of 10 bus loop distribution network is given in Figurem1. This network is energized by using a single generator. It is a $100 \mathrm{MVA}$ base system. In this diagram Bus 0 is a PV bus which is of $11 \mathrm{kV}$ with active power as $1 \mathrm{pu}$ and voltage magnitude as $1 \mathrm{pu}$. Buses from 1-10 are load buses. The active power rating is $1 \mathrm{pu}$ and reactive power rating is $0.5 \mathrm{pu}$. Table 1 describes the power line parameters of the distribution network. By using the above parameters, the voltage magnitude and angles of load buses are calculated using NR method. The steps and equations involved in analysis is given:

Step 1 : Initially, the voltage magnitude of load buses is assumed as 1 and phase angle as 0.

Step 2 : Calculate P and Q using the (1) to (4).

$$
\begin{aligned}
& {[\text { p.ir; p.ii }]=-[\sin (\text { delta }), \cos (\text { delta }) ;-\cos (\text { delta }), \sin (\text { delta })] *[\text { id; iq }] * I} \\
& {[\text { p.vr; p.vi }]=[\sin (\text { delta }), \cos (\text { delta }) ;-\cos (\text { delta }), \sin (\text { delta })] *[\text { vd; vq }] * V} \\
& P=- \text { p. vr } * \text { p. ir }- \text { p. vi } * \text { p. ii } \\
& \text { Q = -p.vi } * \text { p. ir }+ \text { p. vr } * \text { p. ii }
\end{aligned}
$$

Step 3 : Jacobian matrix is formed.

Step 4 : Change in voltage magnitude and angle of load bus is determined using (5) and (6).

$$
\begin{aligned}
& \Delta \mathrm{V}=\operatorname{sqrt}\left(\mathrm{p} . \mathrm{vr}^{\wedge} 2+\mathrm{p} . \mathrm{vi}^{\wedge} 2\right) \\
& \Delta \delta=\operatorname{atan} 2(\mathrm{p} \cdot \mathrm{vi}, \mathrm{p} . \mathrm{vr})
\end{aligned}
$$

Step 6 : The updated value of Voltage and angle is computed by (7) and (8).

$$
\begin{aligned}
& \text { Vnew }=\text { Vold }+\Delta \mathrm{V} \\
& \text { onew }=\delta \text { old }+\Delta \delta
\end{aligned}
$$


Step 7 : The process is repeated from step 2 for next iteration. The iteration is continued until the load buses have minimal error, which is within the specified tolerance level. After completing sufficient iteration, magnitude and angle of voltage in all PQ buses are concluded.

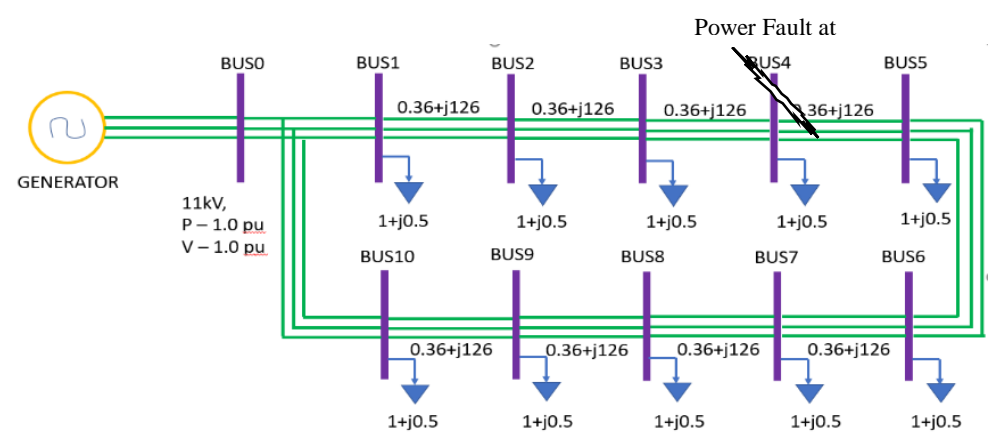

BUS O - GENERATOR BUS OR PV BUS. BUS 1 to 10 - LOAD BUSES OR PQ BUSES.

Figure 1. Single line diagram of 10 bus distribution network

Table 1. Power line parameters

\begin{tabular}{lll}
\hline S. NO & LINE DATA & VALUE \\
\hline 1 & Inductance of line & $1.98 \mathrm{mH}$ \\
2 & Resistance of line & $0.36 \Omega$ \\
3 & Capacitance of line & $25 \mathrm{Mf}$ \\
4 & Length of the Distribution Feeder & $10 \mathrm{~km}$ \\
5 & Line Impedance & $0.36 \mathrm{j} 126 \Omega$ \\
\hline
\end{tabular}

\section{RESULTS AND DISCUSSIONS}

\subsection{Simulation results of distribution system without AVR}

Figure 2 represents the simulation circuit of 10 bus distribution system. The simulation is carried out by using open modelica connection editor. A second order generator is connected as a source for the network. Here, 10 buses are connected in a loop structure. Bus 0 is a generator bus. The remaining buses from 1 to 10 are load buses. To study the load flow analysis and to check stability of the network, a power fault is introduced in Bus 4 during the time interval of 2-3 sec. The change in voltage due to the effect of fault in different buses are analyzed in the simulation results. The electrical components used in this research simulation is taken from Open IPSL library. Table 2 represents the location of various components in OMEdit.

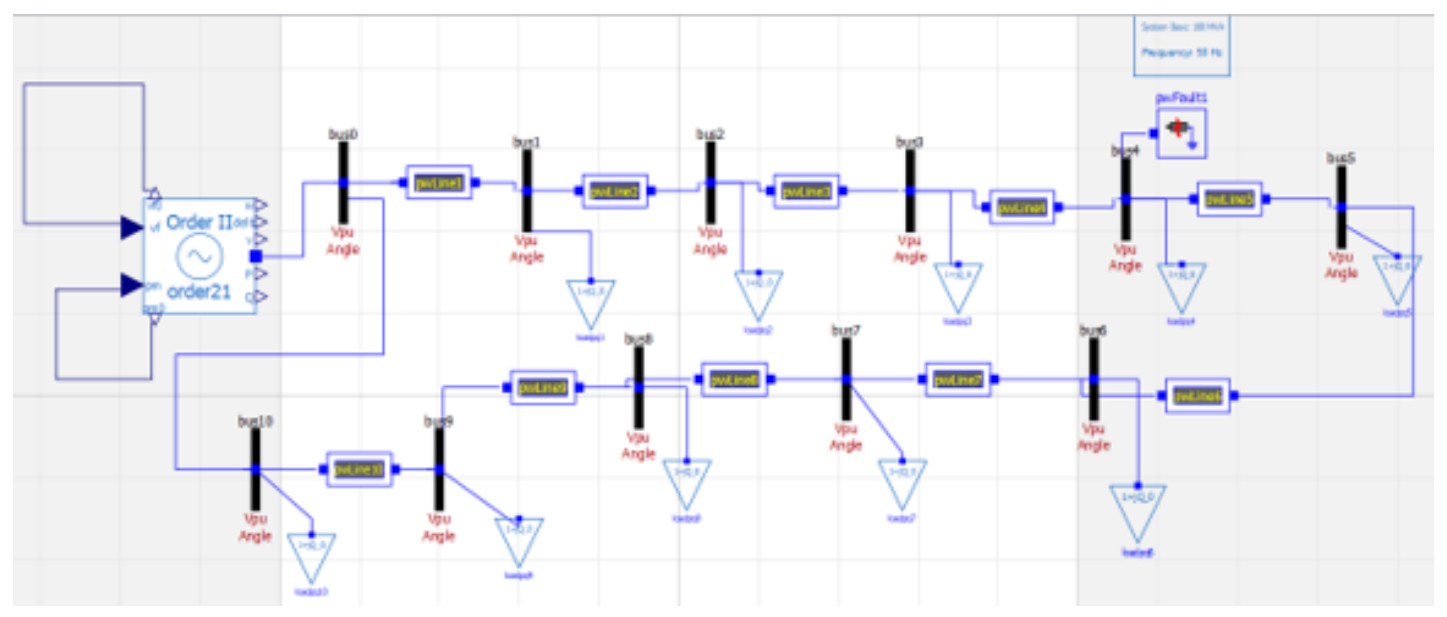

Figure 2. Simulation circuit of 10 bus loop distribution system without AVR 
Table 2. Location of electrical components in OMEdit connector using IPSL

\begin{tabular}{llll}
\hline S. No & Name of the component & Location of component in Open IPSL library & Quantity used \\
\hline 1 & Generator & Open IPSL-Machines-PSAT-second order synchronous Machine & 1 \\
2 & Buses & Open IPSL-Electrical-Buses-Bus & 11 \\
3 & Power line & Open IPSL-Electrical-Branches-PW line & 10 \\
4 & System Base & Open IPSL-Electrical-System base & 1 \\
5 & Constant PQ load & Open IPSL-Electrical-Loads-Constant PQ load & 10 \\
6 & Power Fault & Open IPSL-Electrical-Events-PW fault & 1 \\
7 & Automatic voltage regulator & Open IPSL-Electrical-Controls-PSAT-AVR-AVRTypeIII & 1 \\
8 & Power system stabilizer & Open IPSL-Elecrical-Controls-PSAT-PSS-PSSTypeII & 1 \\
\hline
\end{tabular}

Figure 3 represents the voltage magnitude between bus 1 and 4 . Because of the fault there is a voltage drop in the time duration of $2-3 \mathrm{sec}$. The voltage dip in bus 1 is around $0.2 \mathrm{pu}$ and in bus 4 it is $0.8 \mathrm{pu}$. After $3 \mathrm{sec}$ the buses regains their actual volatges.

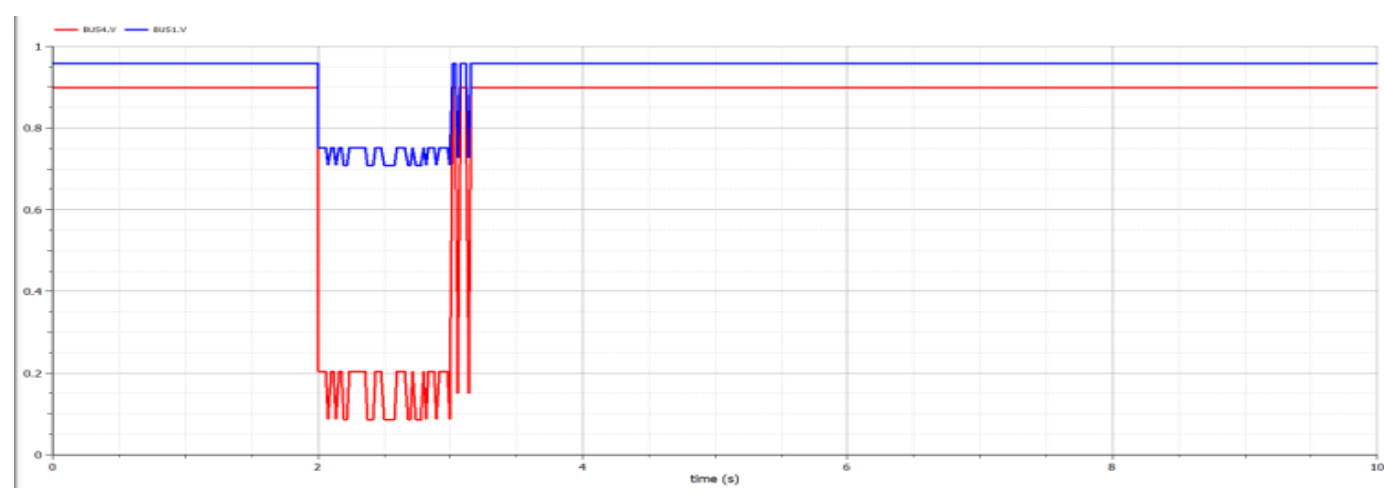

Figure 3 Volatge Magnitude between Bus 1 and Bus 4

The study of voltage between buses 9 and 4 is given in Figure 4. From the graph it is clear that the reduction of voltage observed in bus 9 is approximately $0.2 \mathrm{pu}$. This value is lesser than the fall in voltage magnitude measured in bus 4 . Similarly, Figure 5 represents the voltage suppression in bus 10 due to occurrence of fault in bus 4 . The minimum voltage drop perceived is around $0.05 \mathrm{pu}$ which is minimum when compared to the voltage level observed in other buses connected in the network. Since, bus 10 is very far from fault introduced bus 4 , the voltage suppression level during the prescribed time limit is less.

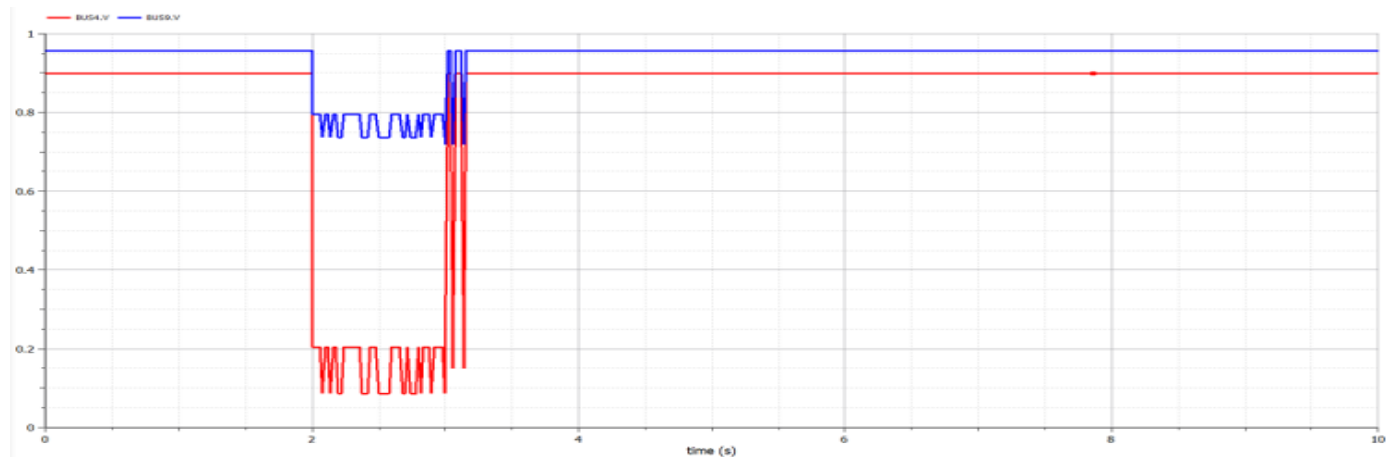

Figure 4. Voltage status of buses 9 and 4

Table 3 gives a view of voltage and angle values for all the 10 buses connected in the network with generator and without AVR. The per unit value of voltage for the buses varies between 0.893 to 0.993 .

Also, the voltage angle varies from 101 to $108 \mathrm{deg}$. From the results, we can observe that during the time interval 2-3 sec all the buses experience a voltage drop before reaching its steady state value. To reduce 
these transients an automatic volatge regualtor alongwith power system stabilizer is connected with the generator. It also helps to enhance the pu voltage of the buses.

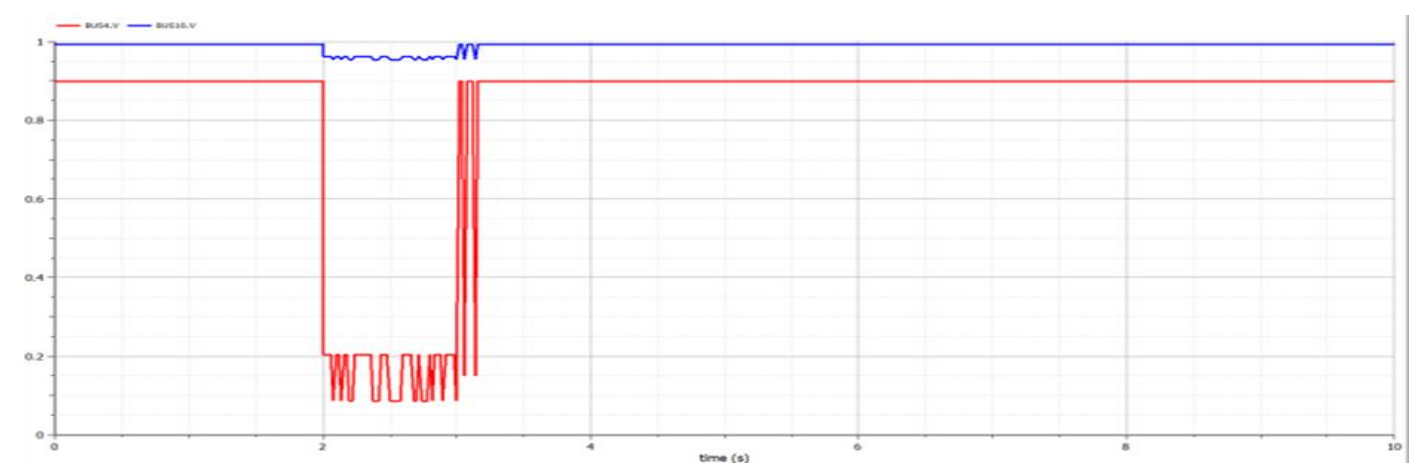

Figure 5. Voltage magnitude observed in bus 10

Table 3. Voltage magnitude and angle profile of 10 bus network without AVR

\begin{tabular}{llll}
\hline S. No & Bus number & Voltage magnitude & Volatge angle \\
\hline 1. & Bus 1 & 0.95771 & 106.183 \\
2 & Bus 2 & 0.930369 & 104.122 \\
3 & Bus 3 & 0.910809 & 102.576 \\
4 & Bus 4 & 0.898692 & 101.619 \\
5 & Bus 5 & 0.893786 & 101.299 \\
6 & Bus 6 & 0.89602 & 101.634 \\
7 & Bus 7 & 0.905495 & 102.615 \\
8 & Bus 8 & 0.926821 & 104.151 \\
9 & Bus 9 & 0.955941 & 106.2 \\
10 & Bus 10 & 0.99322 & 108.667 \\
\hline
\end{tabular}

\subsection{Simulation results of proposed network with AVR and PSS}

Figure 6 represents the simulation diagram of distribution network energized by a generator connected with AVR and PSS. A power faut is given in bus no. 4 between the time interval of 2-3 sec. A third order AVR and second order PSS is selected from IPSL library.

Figure 7 gives information regarding the connection of AVR and PSS with generator. Here, $\mathrm{V}_{\mathrm{f}}$ of AVR is connected with $V_{f}$ of Generator. Connect $V_{f 0}$ to $V_{f 0}$ and $V$ to $V$. Also, the input to PSS is taken from $\mathrm{W}$ of generator. The ouput of PSS is given as input to AVR through $\mathrm{V}_{\mathrm{s}}$ terminal. Pm and Pm0 of generator is interconnected. The power output of generator is given to Bus 0 .

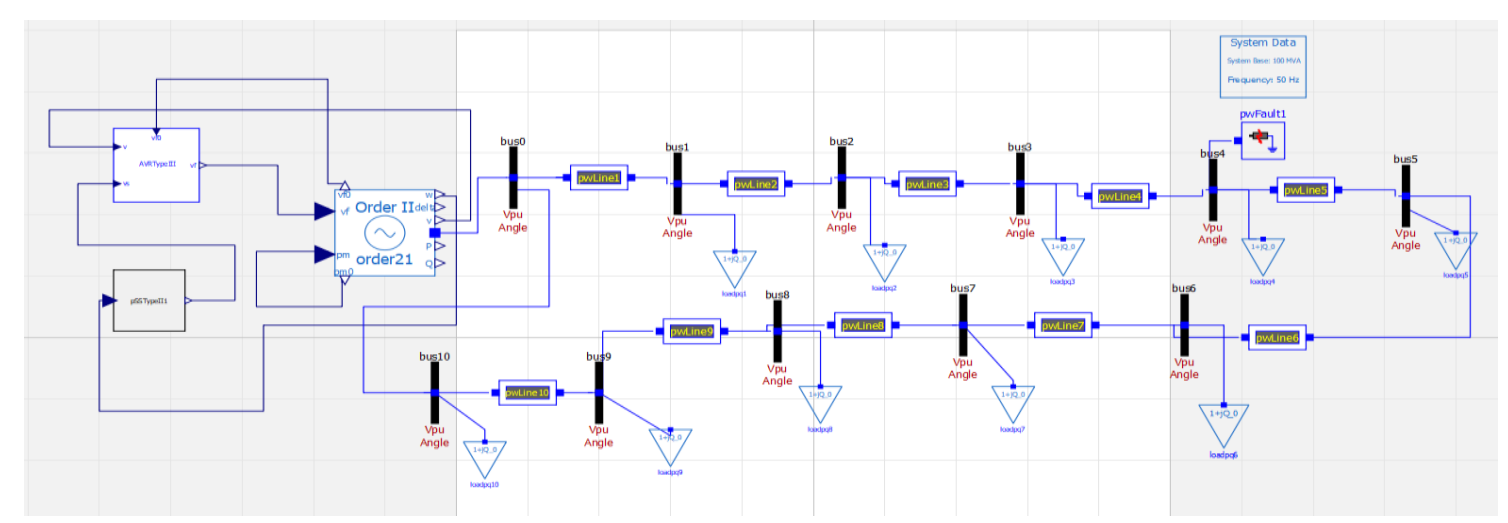

Figure 6. Simulation circuit of proposed network with AVR and PSS

Fig 8 represents the change in voltage during the occurrence of fault in the network. Here, at $0.2 \mathrm{~s}$ Bus 1 volatge has been reduced from $0.99 \mathrm{pu}$ to $0.82 \mathrm{pu}$. So, the drop in it is nearly $0.17 \mathrm{pu}$. At $0.3 \mathrm{~s}$ it attains 
its original value. Bus 4 volatge has a drop of 0.63 pu. Fig 9 represents the voltage drop measured between buses 4 and 9 . The drop in voltage of bus 9 is 0.13 pu which is minimum when compared with bus 4 . Table 4 describes the detailed summary of voltage magnitude and angle of 10 buses. The voltage value differs from $0.978 \mathrm{pu}-0.998 \mathrm{pu}$. Angle of the buses varies between 74.25 to $75.93 \mathrm{deg}$.

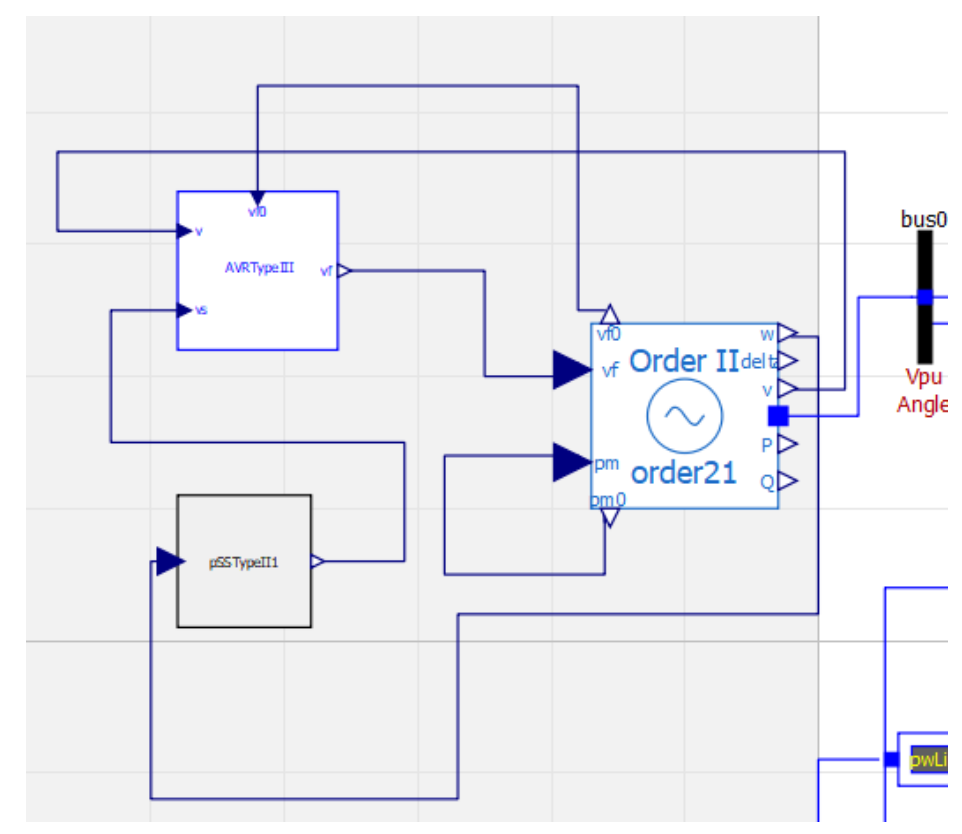

Figure 7. Connection diagram of AVR and PSS with generator

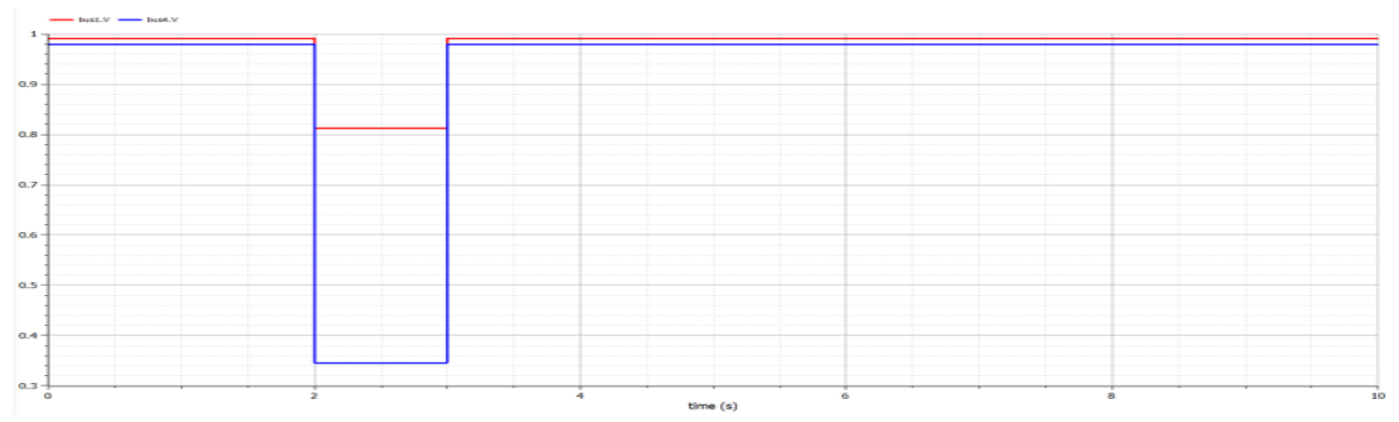

Figure 8. Voltage profile of buses 1 and 4 with AVR

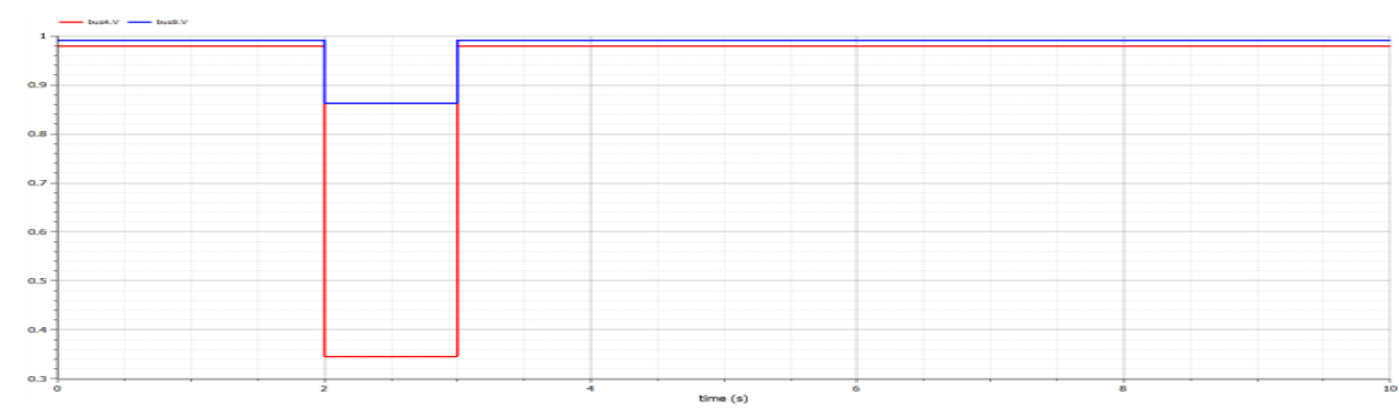

Figure 9. Voltage drop measurement between buses 4 and 9 


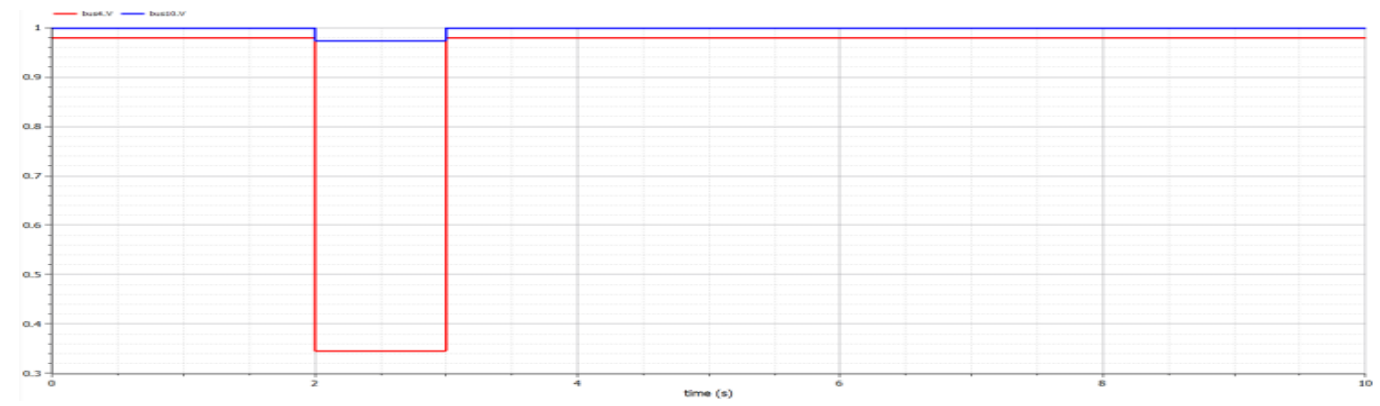

Figure 10. Voltage between buses 4 and 10

Table 4. Outline of voltage magnitude and angle of buses with AVR

\begin{tabular}{llll}
\hline S. No & Bus Number & Voltage Magnitude & Volatge Angle \\
\hline 1. & Bus 1 & 0.991363 & 75.339 \\
2 & Bus 2 & 0.985615 & 74.8671 \\
3 & Bus 3 & 0.981533 & 74.5266 \\
4 & Bus 4 & 0.979096 & 74.3208 \\
5 & Bus 5 & 0.978292 & 74.2518 \\
6 & Bus 6 & 0.979115 & 74.3203 \\
7 & Bus 7 & 0.981572 & 74.5255 \\
8 & Bus 8 & 0.98565 & 74.8661 \\
9 & Bus 9 & 0.991385 & 75.3384 \\
10 & Bus 10 & 0.998804 & 75.9377 \\
\hline
\end{tabular}

\section{COMPARISON OF SIMULATION RESULTS WITH AND WITHOUT AVR}

The per unit voltage of buses 1 to 10 connected with generator is given in Figure 13. From the graph it is understood that the voltage drop exists in all buses between 2-3 sec. This is because of fault simulated in bus 4 at that time interval. So, the drop at bus 4 is more than the drop monitored in other buses. Here, the stable voltage is obtained at $3.2 \mathrm{sec}$. Figure 14 represents the voltage magnitude of the buses in the network connected with AVR. All bus volatges are interrupted at the time interval of 2-3 sec with an injected fault in bus no. 4. Due to this fault, the voltage drop observed in the buses like 3.5 and 6 nearer to bus 4 experience maximum drop. Exactly at 3 ses the fault is cleared and all the buses regains its original voltage.

Table 5 compares various parameters between distribution network with and without AVR. The attributes like Voltage magnitude, Voltage drop in near and far buses, transients and stability of the system have been discussed here. The voltage magnitude of network without AVR varies from 0.893 to 0.993 whereas the system with AVR varies between 0.978-0.998. Also, the drop in near bus is around 0.8pu for the former network and it is about $0.5 \mathrm{pu}$ for the later. Similarly, drop in far bus is $0.05 \mathrm{pu}$ in first case and $0.02 \mathrm{pu}$ in second case. Regarding the transients and stability of the network, AVR implemented network is stable than the other network.

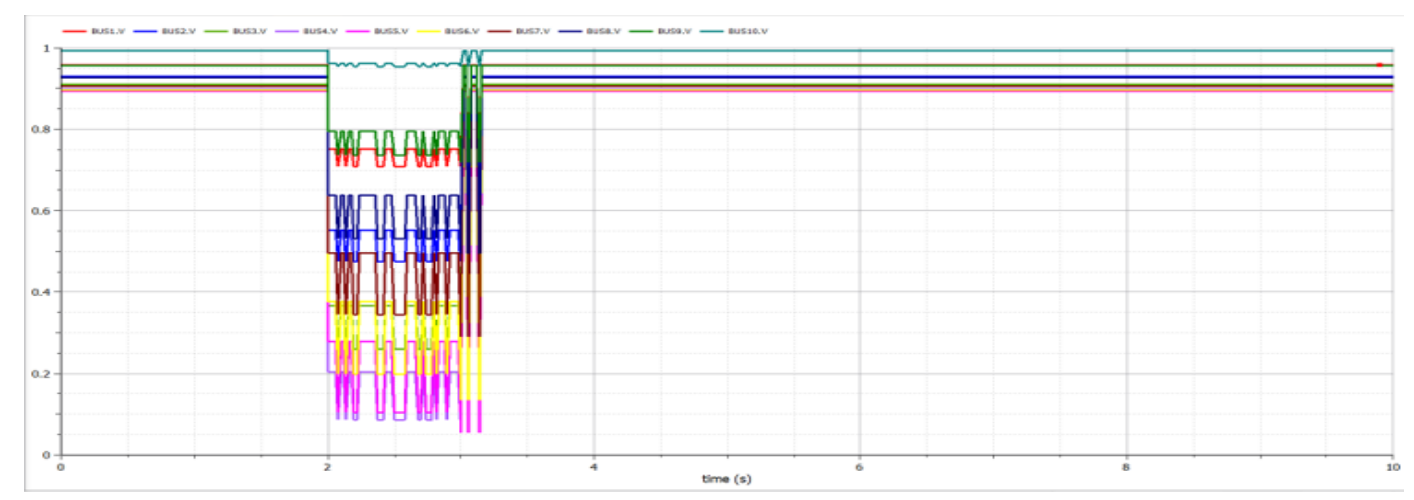

Figure 13. Per unit Voltages spotted in all the buses without AVR 


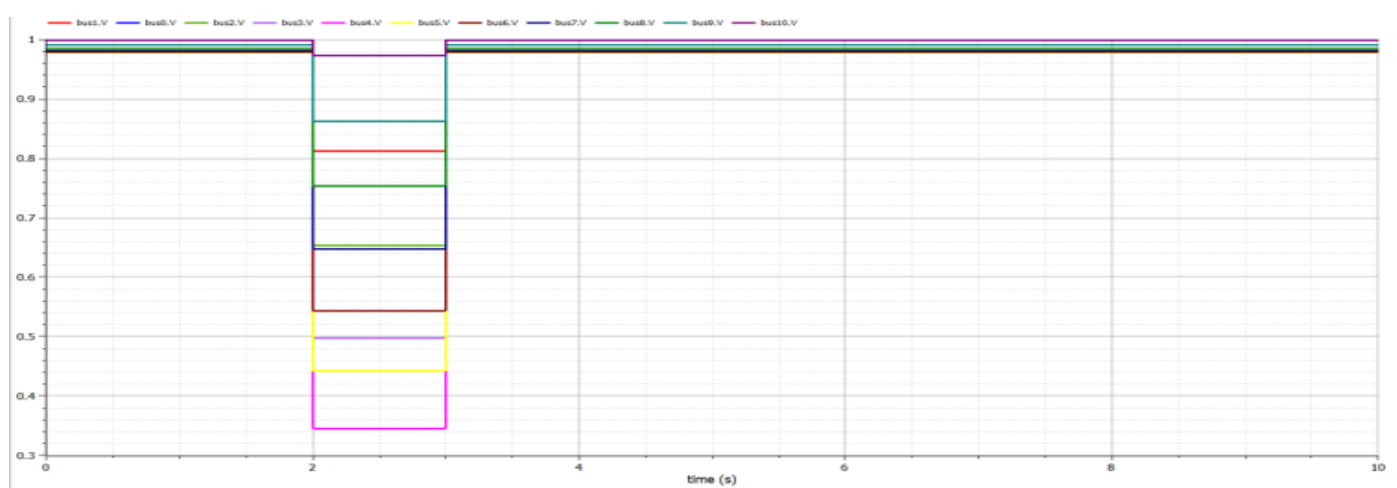

Figure 14. Voltage magnitude of all buses in the network with AVR

Table 5. Comparison between power networks with and without AVR

\begin{tabular}{clll}
\hline S. No & Parameter & Distribution network without AVR & Distribution network with AVR \\
\hline 1. & Volatge magnitude & $0.893-0.993 \mathrm{pu}$ & $0.978-0.998 \mathrm{pu}$ \\
2. & Maximum voltage drop in bus 4 & $0.8 \mathrm{pu}$ & $0.6 \mathrm{pu}$ \\
3. & Maximum voltage drop in bus 5 & $0.8 \mathrm{pu}$ & $0.5 \mathrm{pu}$ \\
4. & Maximum voltage drop in bus 10 & $0.05 \mathrm{pu}$ & $0.02 \mathrm{pu}$ \\
5. & Transients & Present & Absent \\
6. & Stability & Unstable & Stable \\
\hline
\end{tabular}

\section{CONCLUSION}

Thus, from the discussion it is decided that the load flow analysis is carried out to evaluate voltage magnitude and angle of all load buses connected in the loop distribution network using NR method. Also, the voltage stability is analysed by using OMedit simulation. From the simulation results it is observed that the network with AVR controlled generator performs better than the generator excited system. The following points are observed in simulation results of AVR connected system, a) improvement in the voltage stability of the system, b) there is a boost up in the magnitude of the voltage, and c) drop in voltage is reduced during the fault injected time duration. As a future scope, the distribution network can be simulated using matlab for harmonic analysis to guarantee the supply of quality power to the patrons.

\section{REFERENCES}

[1] Awais Farooqi, Muhammad Murtadha Othman, Ahmad Farid Abidin, Shahril Irwan Sulaiman, and Mohd Amran Mohd Radzi, "Mitigation of power quality problems using series active filter in a microgrid system," International Journal of Power Electronics and Drive System (IJPEDS), vol. 10, no. 4, pp. 2245-2253, 2019, DOI: 10.11591/ijpeds.v10.i4.pp2245-2253.

[2] Shradha Singh Parihar, and Nitin Malik, "Load flow analysis of radial distribution system with DG and composite load model," 2018 International Conference on Power Energy, Environment and Intelligent Control (PEEIC), vol. 18, no. 1, pp. 1-5, 2018, DOI: 10.1109/PEEIC.2018.8665424.

[3] Kittaya Somsai, "Controller design of UPQC for enhancing power quality in distribution system," International Journal of Power Electronics and Drive System (IJPEDS), vol. 9, no. 4, pp. 1591-1606, 2018, DOI: 10.11591/ijpeds.v9.i4.pp1591-1606.

[4] Deepinder Kaur Mander, and Supreet Kaur Saini, "Load flow analysis: a review," International Journal of Advanced Research in Electrical, Electronics and Instrumentation Engineering, vol. 5, no. 3, pp. 1254-1260, 2016, DOI: 10.15662/IJAREEIE.2016.0503009.

[5] Bouanane Abdelkrim, and Yahiaoui Merzoug, "Robust stability power in the transmission line with the use of a UPFC system and neural controllers based adaptive control," International Journal of Power Electronics and Drive System (IJPEDS), vol. 10, no. 3, pp. 1281-1296, 2019, DOI: 10.11591/ijpeds.v10.i3.pp1281-1296.

[6] P. Abirami, and Merin Lizbeth George, "Implementation of NN Controlled DVR for Enhancing the Power Quality by Mitigating Harmonics," International Journal of Power Electronics and Drive System (IJPEDS), vol. 9, no. 2, pp. 738-743, 2018, DOI: 10.11591/ijpeds.v9.i2.pp738-743.

[7] Thirumoorthi. P, T.D. Raheni, "Adaptive method for power quality improvement through minimization of harmonics using artificial intelligence," International Journal of Power Electronics and Drive System (IJPEDS), vol. 8, no. 1, pp. 470-482, 2017, DOI: 10.11591/ijpeds.v8.i1.pp470-482.

[8] K. Swetha, and V. Sivachidambaranathan, "A review on different control techniques using DSTATCOM for distribution system studies," International Journal of Power Electronics and Drive System (IJPEDS), vol. 10, no. 2, pp. 813-821, 2019, DOI: 10.11591/ijpeds.v10.i2.pp813-821. 
[9] Tanveer Husain, Muqueem Khan, and Mujtahid Ansari, "Power flow analysis of distribution system," International Journal of Advanced Research in Electrical, Electronics and Instrumentation Engineering, vol. 5, no. 5, pp. 40584066, 2016, DOI: 10.15662/IJAREEIE.2016.0505108.

[10] Abdellatif Hinda, Mounir Khiat, and Zinelaabidine Boudjema, "Advanced control scheme of a unifiedpower flow controller using sliding mode control," International Journal of Power Electronics and Drive System (IJPEDS), vol. 11, no. 2, pp. 625-633, 2020, DOI: 10.11591/ijpeds.v11.i2.pp625-633.

[11] Labed Imen, and Labed Djamel, "Power flow variation based on extreme learning machine algorithm in power system," International Journal of Power Electronics and Drive System (IJPEDS), vol. 10, no. 3, pp. 1244-1254, 2019, DOI: 10.11591/ijpeds.v10.i3.pp1244-1254.

[12] Muhammad Alif Mansor, Muhammad Murtadha Othman, Ismail Musirin, and Siti Zaliha Mohammad Noor, "Dynamic voltage restorer (DVR) in a complex voltage disturbance compensation," International Journal of Power Electronics and Drive System (IJPEDS), vol. 10, no. 4, pp. 2222-2230, 2019, DOI: 10.11591/ijpeds.v10.i4.pp22222230.

[13] Mohammed Albadi, Power flow analysis, IntechOpen, Book Chapter, 2019.

[14] Ali M. Eltamaly, Yehia Sayed, Abou-Hashema M. El-Sayed, and Amer Nasr A. Elghaffar, "Optimum power flow analysis by newton raphson method, a case study," International Journal of Engineering, vol. 16, no. 4, pp. 51-58, 2018.

[15] Nitesh Kumar Lal, and Samina Elyas Mubeen, "A review on load flow analysis," International Journal of Innovative Research and Development, vol. 3, no. 11, pp. 337-341, 2014.

[16] Sivkumar Mishra, and Debapriya Das, "Distribution system load flow methods: a review," Journal of Electrical \& Electronics Engineering, vol. 1, no. 2, pp. 1-25, 2008.

[17] Dharamjit, and D.K. Tanti, "Load flow analysis on IEEE 30 bus system," International Journal of Scientific and Research Publications, vol. 2, no. 11, pp. 1-6, 2012.

[18] Archita Vijayvargia, Sweety Jain, Sneha Meena, and Vinita Gupta, "Comparison between different load flow methodologies by analyzing various bus systems," International Journal of Electrical Engineering, vol. 9, no. 2, pp. 127-138, 2016.

[19] Venkata Krishna. B, and Padma Srinivasu. N, "A direct method for distribution system load flow solutions," International Journal of Engineering and Advanced Technology (IJEAT), vol. 8, no. 6, pp. 749-753, 2019, DOI: 10.35940/ijeat.F1138.0986S319.

[20] Zain Anwer Memon, Riccardo Trinchero, Yanzhao Xie, Flavio G. Canavero, and Igor S. Stievano, "An iterative scheme for the power-flow analysis of distribution networks based on decoupled circuit equivalents in the phasor domain," Energies, vol. 13, no. 2, pp. 1-16, 2020, DOI: 10.3390/en13020386.

[21] Prakash Ch. Tah, Anup K. Panda, and Bibhu P. Panigrahi, "Shunt active filter based on radial basis function neural network and p-q power theory," International Journal of Power Electronics and Drive System (IJPEDS), vol. 8, no. 2, pp. 667-676, 2017, DOI: 10.11591/ijpeds.v8.i2.pp667-676.

[22] Diego Issicaba and Jorge Coelho, "Convergence evaluation of a load flow method based on cespedes' approach to distribution system analysis," International Journal of Electrical and Computer Engineering (IJECE), vol. 6, no. 6, pp. 3276-3282, 2016, DOI: 10.11591/ijece.v6i6.pp3276-3282.

[23] Kriti Singhal, "Comparison between load flow analysis methods in power system using MATLAB," International Journal of Scientific \& Engineering Research, vol. 5, no. 5, pp. 1412-1419, 2014.

[24] Ravi Teja Bhimarasetti, and Ashwani Kumar, "A new contribution to distribution load flow analysis for radial and mesh distribution systems," 2014 International Conference on Computational Intelligence and Communication Networks, 2014, vol. 6, no. 1, pp. 1229-1236, DOI: 10.1109/CICN.2014.255.

[25] L.Vanfretti, W. Li, T. Bogodorova and P. Panciatici, "Unambiguous power system dynamic modeling and simulation using modelica tools," 2013 IEEE Power \& Energy Society General Meeting, 2013, pp. 1-5, DOI: 10.1109/PESMG.2013.6672476. 